Jurnal Pemberdayaan: Publikasi Hasil Pengabdian kepada Masyarakat

Vol. 3, No. 2, Agustus 2019, Hal. 237-240

ISSN: 2580-2569; e-ISSN: 2656-0542

DOI: https://doi.org/10.12928/jp.v3i2.778

\title{
Pelatihan pembuatan lilin aromaterapi di Pedukuhan Jangkang Lor, Sentolo, Kulonprogo
}

\author{
Hasrul Rahman, Hanif Rahman Adi, Dian Yuliani, Rinah \\ Universitas Ahmad Dahlan, Jl. Ring Road Selatan, Banguntapan, Bantul, Indonesia \\ Email: hasrul.rahman@pbsi.uad.ac.id
}

\begin{abstract}
ABSTRAK
Kreativitas sangat dibutuhkan dalam kehidupan bermasyarakat saat ini. Salah satu tujuannya adalah untuk mendongkrak perekonomian dalam negeri. Pelatihan pembuatan lilin aromaterapi adalah salah satu cara untuk menghasilkan produk yang dapat menjadi sebuah sumber penghasilan yang bernilai jual tinggi. Pelatihan pembuatan lilin aromaterapi ini dilaksanakan di pedukuhan Jangkang Lor, Kabupaten Kulonprogo. Dengan diadakannya pelatihan ini masyarakat pedukuhan Jangkang Lor dapat memahami teori dan praktik pembuatan lilin aromaterapi. Setelah pelatihan ini selesai diharapkan masyarakat dapat mengembangkan lebih lanjut, agar bisa dijadikan sebagai sarana untuk menghasilkan sumber penghasilan bagi masyarakat setempat.
\end{abstract}

Kata Kunci : Pelatihan, Lilin Aromaterapi, Jangkang Lor

\section{ABSTRACT}

Creativity is needed in today's social life. One goal is to boost the domestic economy. Training on making aromatherapy candles is one way to produce products that can be a source of income that has a high selling value. The training in making aromatherapy candles was carried out in the Jangkang Lor hamlet, Kulon Progo Regency. With this training, the people of Jangkang Lor village can understand the theory and practice of making aromatherapy candles. After the training is complete, it is expected that the community can develop further, so that it can be used as a means to generate sources of income for the local community.

Keywords: Training, Aromatherapy Candles, Jangkang Lor

\section{PENDAHULUAN}

Indonesia merupakan negara yang kaya akan sumber daya alam hayati sehingga dijuluki negara agraris. Namun, sampai saat ini pemanfaatan sumberdaya hayatinya belum optimal, salah satunya adalah tanaman penghasil minyak atsiri. Indonesia menghasilkan 40-50 jenis tanaman penghasil minyak atsiri dari 80 jenis minyak atsiri yang diperdagangkan di dunia dan baru sebagian dari jenis minyak atsiri tersebut yang memasuki pasar dunia, diantaranya nilam, sereh wangi, gaharu, cengkeh, melati, kenanga, kayu putih, cendana, dan akar wangi (Faidliyah, 2017). Tanaman tersebut tentunya sangat mudah ditemukan dan dibudidayakan di Indonesia, salah satunya di Pedukuhan Jangkang Lor yang mayoritas penduduknya bekerja di ladang yang pendapatannya tidak menentu.

Pedukuhan Jangkang Lor terletak di Desa Sentolo, Kecamatan Sentolo, Kabupaten Kulon Progo. Keadaan wilayah di Pedukuhan Jangkang Lor rata-rata memiliki tanah berkapur dan tanah liat. Pada musim hujan biasanya ditanam pohon jagung sehingga membutuhkan alternatif lain untuk mengembangkan usaha rumahan bagi masyarakat setempat. Dengan adanya pelatihan pembuatan lilin aromaterapi diharapkan masyarakat setempat menjadi lebih kreatif untuk memajukan sektor kerajinan yang lainnya agar dapat menambah penghasilan dan meningkatkan perekonomian. 
Lilin aromaterapi memiliki banyak sekali manfaat. Apalagi untuk masyarakat yang kesibukannya sangat tinggi. Salah satu manfaatnya ialah untuk meredakan tingkat stres. Lilin aromaterapi sangat cocok untuk dikembangkan produknya di Kota Yogyakarta yang menjadi salah satu tempat wisata bagi masyarakat Indonesia maupun dunia. Dengan adanya pelatihan ini diharapkan masyarakat Pedukuhan Jangkang Lor dapat menjadi pemasok lilin aromaterapi ke hotel-hotel yang berada di kota Yogyakarta.

\section{METODE}

Untuk mencapai tujuan yang diharapkan, pelatihan di Pedukuhan Jangkang Lor dilakukan melalui penyuluhan, pelatihan sekaligus praktik langsung dalam membuat lilin armaterapi. Adapun ringkasan metode pelaksanaan kegiatannya ada pada tabel 1.

Tabel 1. Metode dan kegiatan pelatihan pembuatan lilin aromaterapi

\begin{tabular}{llll}
\hline No. & Metode & Kegiatan & \\
\hline 1 & $\begin{array}{l}\text { Penyampaian } \\
\text { Materi }\end{array}$ & $\begin{array}{l}\text { Penyuluhan untuk memperkenalkan berbagai tanaman } \\
\text { penghasil minyak atsisri yang dapat digunakan sebagai } \\
\text { aromaterapi. }\end{array}$ \\
2 & Praktik & Pelatihan Pembuatan Lilin Aromaterapi & \\
\hline
\end{tabular}

\section{HASIL, PEMBAHASAN, DAN DAMPAK}

\section{Penyampaian Materi Tentang Lilin Aromaterapi}

Kegiatan sosialisasi dan praktik diadakan 3 kali, supaya masyarakat lebih memahami secara mendalam tentang proses pembuatannya. Pelatihan ini berguna untuk menambah wawasan serta memberikan pengetahuan baru tentang proses pembuatan lilin aromaterapi dengan skala rumah tangga.

Lilin aromaterapi biasanya merupakan aromaterapi secara inhalasi (penghirupan), yaitu penghirupan uap aroma yang dihasilkan dari beberapa tetes minyak atsiri dalam wadah berisi air panas, salah satu aplikasi aromaterapi menggunakan media lilin. Lilin aromaterapi akan menghasilkan aroma yang memberikan efek terapi bila dibakar. Aroma lilin dihasilkan dari minyak atsiri yang tergolong ke dalam jenis aroma yang mampu memberikan efek terapi menenangkan dan merilekskan (Primadiati, 2002).

Alat yang diperlukan dalam pelatihan ini adalah kompor, panic, mangkok logam, sendok, wadah kecil, sedotan kecil, Bahan yang diperlukan dalam pelatihan ini adalah wax (parafin wax), stearin sebagai pengeras wax yang gampang meleleh (tipe wax yang tahan temperatur tinggi), pewarna, sumbu untuk lilin dan aromateraphy oil.

Cara pembuatan lilin aromaterapi adalah sebagai berikut: disiapkan bahan dan alat pembuatan lilin aromaterapi; dipanaskan parafin menggunakan mangkok logam di dalam panci yang sudah berisi air; ditunggu hingga parafin mencair, setelah itu ditambahkan stearin sebanyak satu sendok; diaduk hingga rata, kemudian ditambahkan pewarna dan aromaterapi sebanyak 1-2 tetes; setelah tercampur rata, dituangkan ke dalam wadah dan ditambahkan sumbu pada bagian tengah lilin; ditunggu hingga dingin lilin aromaterapi siap digunakan.

Manfaat yang dapat diambil dari lilin aromaterapi ini adalah: meringankan pikiran dan mengurangi stress; membangkitkan semangat; membersihkan racun dalam tubuh; 
peningkatan memori jangka panjang; pencegahan rambut rontok; pengurangan eksim gatal; mencegah insomnia; membersihkan udara dan penangkalan kuman (library.binus.ac.id, 2019).

\section{Praktik Pembuatan Lilin Aromaterapi}

Gambaran antusias masyarakat Pedukuhan Jangkang Lor dalam pelaksanaan pelatihan tersebut tersaji pada gambar 1 .

Dampak dari pelatihan pembuatan lilin aromaterapi adalah masyarakat paham dengan teori dan cara pembuatan lilin aromaterapi, selain itu masyarakat dapat berinovasi untuk membuat bentuk dan aroma lilin yang beragam. Pelatihan ini disambut dengan antusias oleh masyarakat Pedukuhan Jangkang Lor. Di samping itu, banyak sekali manfaat yang dapat dikembangkan lebih jauh lagi dengan adanya pelatihan ini. Masyarakat setidaknya dapat bersaing di era industri 4.0 seperti sekarang ini. Di era seperti sekarang tentunya menuntut masyarakat untuk bisa mengembangkan pengetahuannya agar pelatihan seperti ini dapat memunculkan gairah dalam berwirausaha dan menompang perekonomian. Dengan adanya pelatihan ini masyarakat akan mampu mengembangkan industri kreatifnya ke arah yang lebih besar sehingga dapat berperan penting dalam kemajuan Pedukuhan Jangkang Lor khususnya.
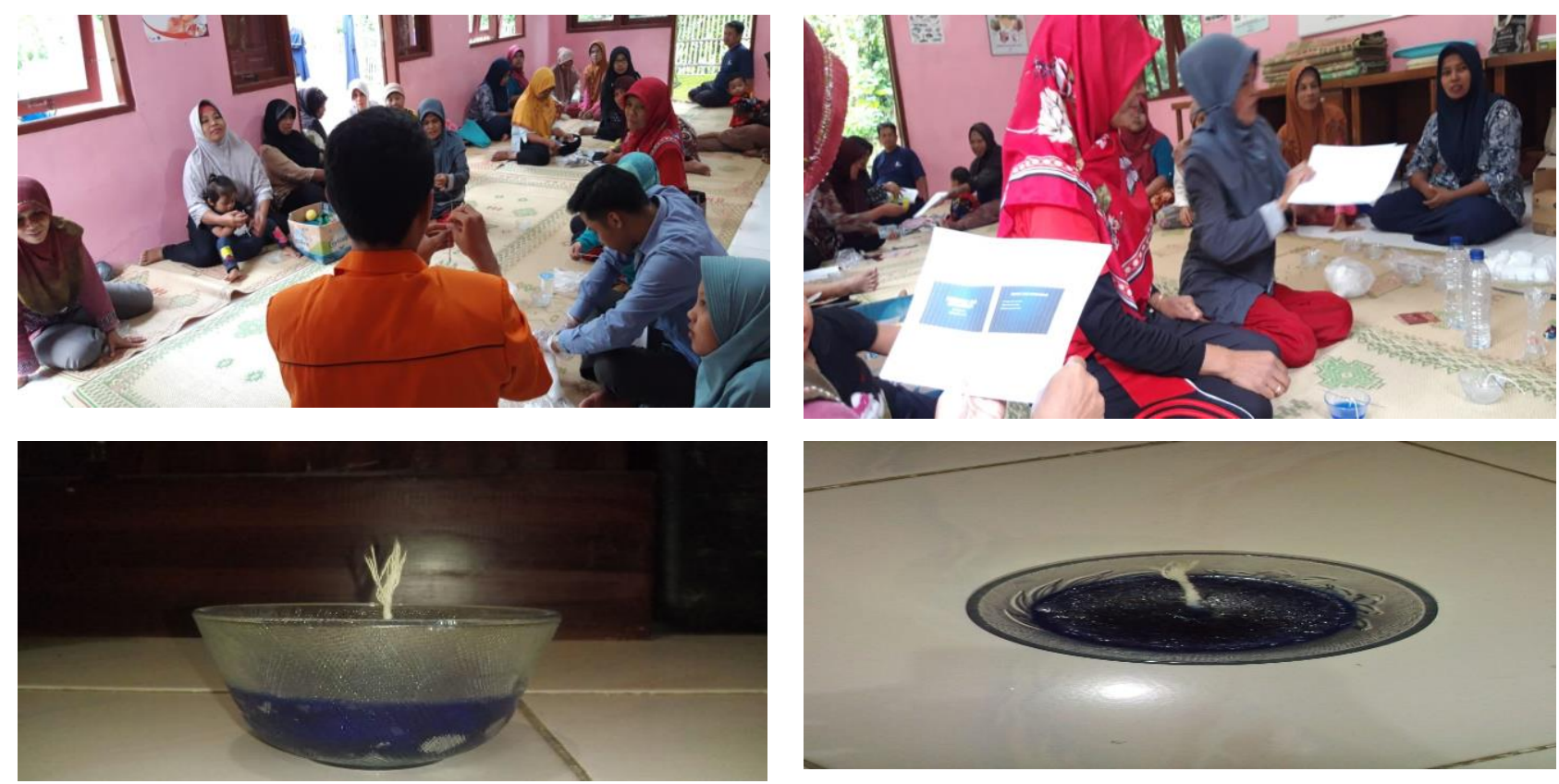

Gambar 1. Antusias masyarakat Pedukuhan Jangkang Lor dalam pelaksanaan pelatihan

\section{SIMPULAN}

Pelatihan pembuatan lilin armaterapi telah berjalan dengan baik, tingkat partisipasi masyarakat Pedukuhan Jangkang Lor untuk dapat mengikuti pelatihan pembuatan lilin aromaterapi tinggi, antusias dan responsif. Masyarakat Pedukuhan Jangkang Lor sudah memahami teori dan praktik dalam membuat lilin aromaterapi..

\section{UCAPAN TERIMAKASIH}

Terima kasih kami sampaikan kepada Lembaga Penelitian dan Pengabdian Masyarakat (LPPM) Universitas Ahmad Dahlan Yogyakarta atas bantuannya, sehingga program ini dapat berjalan. 


\section{DAFTAR PUSTAKA}

Faidliyah. (2017). Pembuatan Lilin Aroma Terapi Berbasis Bahan Alami. Jurnal Prodi Teknik Kimia Intitut Teknologi Malang.

http://library.binus.ac.id/eColls/eThesisdoc/Bab2/2012-2-01732-DS\%20Bab2001.pdf., tanggal 13 Maret 2019.

Primadiati, R., (2002). Aromaterapi: perawatan alami untuk sehat dan cantik. Jakarta: PT Gramedia Pustaka Utama. 